\title{
Quest for identity: linking ethnicity, electoral politics and violence in Koch-Rajbanshi sovereignty movements of India
}

\author{
Chandreyi Sengupta ${ }^{1}$, Debajit Datta ${ }^{* 1}$ \\ ${ }^{1}$ Jadavpur University, Kolkata, India
}

Ethnic groups involved in separatist movements have often been engaged in violence, rather than electoral politics, in order to fulfil their demands. The present paper analyses the dynamics of the sovereignty movements of the Koch-Rajbanshi community of northeastern India, an indigenous group that has used active and suppressed violence for accomplishing their demands along with electoral contests. Nuanced analyses of literature, electoral information, schedule-based surveys and personal interviews of Koch-Rajbanshi respondents were used for this purpose. Results indicated that most elected KochRajbanshi representatives belonged to mainstream political parties and failed to bring about practical solutions for the sovereignty issue. The pro-sovereignty outfits were unable to gain electoral success and further hindered the movement. Fear of backlash from the ruling party also stopped many Koch-Rajbanshi commons from being involved in the electoral process. Accordingly, adequate electoral representation of Koch-Rajbanshi political groups was identified as the only democratic solution to this escalating conflict.

Key Words: Bengali immigrant, common property resource, electoral politics, identity conflict, Koch-Rajbanshi, social hierarchy.

Article Info: Received: October 25, 2018; Revised: April 17, 2019; Accepted: May 17, 2019; Online: May 31, 2019.

\section{${ }^{*}$ Corresponding author}

Address: Department of Geography, Jadavpur University, 188, Raja S.C. Mallick Road, Kolkata Phone: +0918910308855 | Email: chandreyisengupta@gmail.com

(C)2019 Human Geographies; The authors

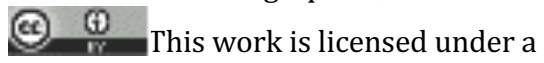

Creative Commons Attribution 4.0 International License. DOI:10.5719/hgeo.2019.131.6 


\section{Introduction}

Violent insurgencies and electoral politics have often been considered as tactical alternatives in a political movement since conflicting groups may either use aggression or participate in democratic elections to accomplish their goals (Buendia, 2005; South, 2008). Conversely, these may be treated as complementary phenomena when force is used as a way of securing a large vote bank to ensure electoral success (Dunning, 2011). It has also been frequently observed that lack of political organisation resulting in an eventual electoral debacle, may propel political groups towards using violence as the only means to achieve their ends. Usually, ethnic communities making separatist demands have been found to follow such paths as they often fail to garner sufficient political backing (Brown, 1988; Tan-Mullins, 2006).

In the north-eastern states of India, nationalist movements have acquired a formidable character because of incompetent management of ethnic issues by the central as well as state governments (Cline, 2006). Violent conflicts by the Bodo tribe in Assam, the Naga and Kuki tribes in Nagaland and Manipur, the Gorkhas in Darjeeling of West Bengal and the Koch-Rajbanshi (KR) community in the Dooars region of northern West Bengal and western Assam have continued to afflict the country since its independence from the British rule (Nandi, 2002). The KR sovereignty movement is essentially a manifestation of the reactions of not only the KR community but also the other indigenous groups of this region against the ethnocratic treatment dispensed towards them by their respective states under the Indian federation. Subsequently, KR activists have resorted to direct as well as suppressed violence since the early twentieth century to attain separate statehood in this region (Bhadra, 2004). The moderate factions of these activists have also been engaged with the regional electoral politics since the last decade in an attempt to obtain a democratic solution to their demands. Interactions of these groups with mainstream political parties coupled with the vigorous aggression of extremist $\mathrm{KR}$ protestors have generated a volatile political landscape in this region that, in turn, has been affecting its physical as well as socio-economic environment (Das, 2009). In this backdrop, the present paper focused upon these dynamics and sought to explore the linkages of this movement with the electoral politics of the selected study area. An assessment of the role played by the KR community in the electoral politics of this region as well as the interactions of the KR sovereignty movement and consequent insurgencies with the regional electoral politics was also conducted in this context.

\section{Background of the study}

The KR sovereignty movement primarily originated as a conflict over resources between the indigenous and immigrant groups of the Dooars region of northern West Bengal and western Assam. The roots of this movement should ideally be 
traced back to the colonial period when the introduction of tea plantations by British administrators stimulated the immigration of tribal populations from neighbouring states and thereby altered the regional population dynamics (Bhadra, 2004). Plantations were introduced at the expense of forestlands that caused considerable disgruntlement among the indigenous groups of the region like the Rabha, Mech, Toto and the KR who had always shared symbiotic relationships with the forests (Nandi, 2002). Concurrently, the British also began to encourage the practice of sedentary cultivation in the Dooars along with imposing restrictions on the use of forest products and hunting. While the immigrant tribal populace proved to be quite efficient sedentary cultivators, all indigenous groups, except the KR community, struggled to cope with the new system as they were used to the practices of shifting cultivation and hunting for livelihood (Sengupta \& Datta, 2016). Consequently, the native Rabha, Mech and Toto tribes were pushed into the lowest rungs of the existing social order whereas the KR community continued to occupy the peak of the regional socio-economic hierarchy due to its expertise in sedentary agriculture and ownership of considerable proportions of land (Nandi, 2002).

However, this prevailing socio-economic hierarchy of the Dooars underwent a noticeable transformation after Indian independence and partition in 1947 that produced a mass movement of primarily Hindu Bengali immigrants from erstwhile East Pakistan into the region. These immigrants were locally known as the Bhatiya (Das, 2009). Many of them were knowledgeable in innovative techniques of sedentary farming and proved to be more industrious as well as astute than all other communities inhabiting the region. They accrued agricultural lands and other properties from the comparatively more gullible sections of the KR landowners at trifling prices and gradually replaced this native group as the dominant community of the region in terms of socio-economic and political clouts (Nandi, 2002; Barman, 2011). The Bhatiya also began to indulge in severe cultural ostracisation of the indigenous groups, especially the KR, which infuriated them further (Das, 2009). Consequently, the marginalised KR masses began to demand a separate homeland for themselves to regain economic security and preserve their culture from outsiders and resorted to direct as well as suppressed violence for that purpose (Table 1).

$\underline{\text { Table 1. Instances of violence perpetrated by KR outfits in the region in last two decades }}$

\begin{tabular}{lccc}
\hline \multicolumn{1}{c}{ Incident } & $\begin{array}{c}\text { Fre- } \\
\text { quency }\end{array}$ & $\begin{array}{c}\text { Year of } \\
\text { occurrence }\end{array}$ & Affected group / institution \\
\hline $\begin{array}{l}\text { Plundering } \\
\text { Kidnapping and }\end{array}$ & 1 & 1999 & Railway cash counter \\
extortion & 2 & 1999,2009 & Bhatiya businessmen \\
Assassination & 11 & 2000,2001, & Bhatiya individuals, \\
& 3 & $2000,2006,2013$ & Several Bhatiya and KR commons \\
Explosions & 8 & 2005,2016 & Policemen, KR activists, train passengers \\
$\begin{array}{l}\text { Death during a strike } \\
\text { Injuries during a strike }\end{array}$ & 3 & $2005,2011,2016$ & Several KR activists, Policemen \\
Damage to property & 2 & 2005,2011 & Several KR activists, Bhatiya commons \\
\hline Source: South Asia Terrorism Portal, 2018; Mehta, 2016 &
\end{tabular}


The proposed homeland was given different names such as 'Kamatapur' or the 'Greater Cooch Behar' although its geopolitical boundaries remained roughly the same (Mehta, 2016). In reality, most KR political outfits were content with the demand for a separate federal unit within India except few extremist organisations, which demanded a separate nation. Although the Rabha and Mech tribes had remained dispassionate towards the KR sovereignty movement during its initial stages, they joined it subsequently, claiming that resources of the region belonged more to the aboriginal communities than the immigrants. A significant share of their grievances was directed towards administrative authorities who had continued to impose restrictions upon their usage of common property resources (CPRs) even during the post-colonial period. The dissatisfaction that had been festering among them for ages finally found expression through the sovereignty movement (Nandi, 2002).

\section{Methods and study area}

A hybrid methodological framework incorporating both qualitative and quantitative analyses was adopted for the present study. The relevant research questions framed to attain the research objectives were, (1) how does the electoral performance of the KR community affect its quest for sovereignty? (2) what are the major facets of distribution of political power emerging through the different interactions among the Bhatiya and KR communities? (3) what are the prime consequences of the prevailing regional electoral politics on KR insurgencies? Accordingly, the methods applied for this purpose include a selection of study area, evaluation of the role of KR community in electoral politics, and assessment of the impacts of KR electoral achievements on the sovereignty movement.

\section{Study area}

The KR community resides predominantly in the Dooars region of the states of West Bengal and Assam. However, most of the political activities relating to the KR sovereignty movement had been concentrated in and around the district of Koch Bihar in West Bengal during the last few decades. Accordingly, this district was selected as the study area for the present research (Figure 1).

The ethnic composition of Koch Bihar exhibits considerable diversity with indigenous communities such as the KR, Rabha and Mech as well as immigrants from other parts of West Bengal, neighbouring states and countries (Das, 2009). While the KR community has been categorized as Scheduled Caste (SC) in West Bengal, the Rabha and Mech have been designated with Scheduled Tribe (ST) status (GoI, 2011). Immigrants primarily consist of the Bengali speaking Hindu and Muslim populations. The KR community comprises almost $75.2 \%$ of the total SC population and $37.75 \%(1,064,413$ persons $)$ of the total population of the district (GoI, 2011). 


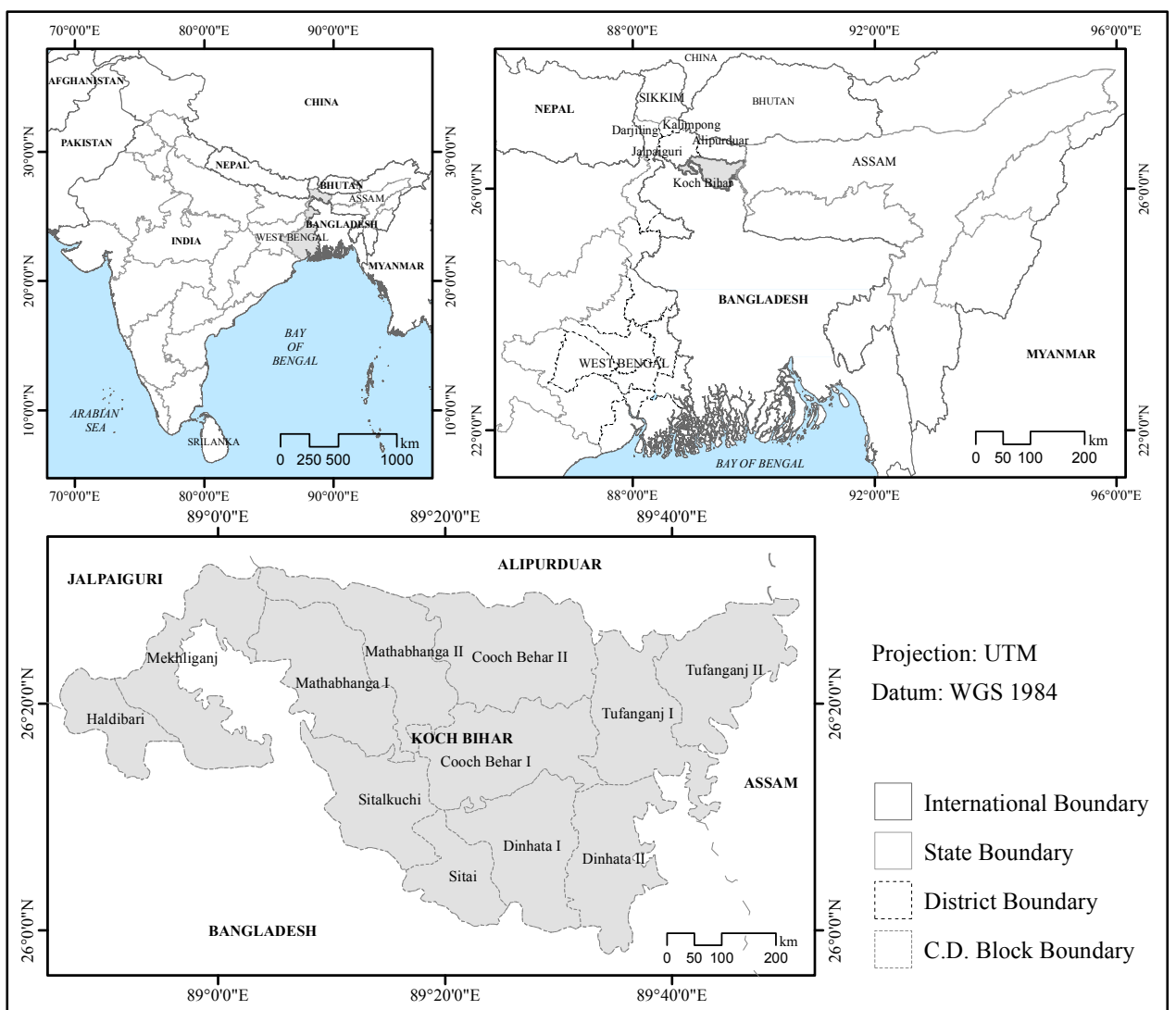

Figure 1. Location of the study area

The administrative set-up of Koch Bihar is constituted of 12 Community Development (C.D.) Blocks as well as six urban municipalities. As far as the electoral structure of the district is concerned, it is akin to the rest of India and consists of the Parliamentary as well as the three-tiered Panchayat system. Koch Bihar has nine constituencies at the legislative Assembly level under the Parliamentary system. In contrast, the Panchayat system is a form of local selfgovernance practiced in rural India. It is composed of the lowest Gram Panchayat (GP) tier corresponding to the village level, the intermediate Panchayat Samity (PS) analogous to the C.D. Block level, and the highest Zila Parishad (ZP) representing the district level. In Koch Bihar, there are 128 GPs, 12 PSs and 1 ZP under this system (GoWB, 2018).

\section{Evaluation of the role of KR community in electoral politics}

Data relating to the Panchayat election of Koch Bihar for the year 2013 were collected from the official website of the state government (West Bengali State Election Commission, 2018) and used to analyse current electoral politics in the study area, as well as to understand the role of KR community in it. Results of the Assembly elections of Koch Bihar from 1962 to 2016 were obtained online from 
www.elections.in (2018a, 2018b, 2018c, 2018d, 2018e, 2018f, 2018g, 2018h, 2018i, 2018j, 2018k, 2018l, 2018m) and Statistics Time (2018) and evaluated in order to comprehend the historical electoral positioning of the KR community at the Assembly level. Location Quotients were calculated based on the results of Panchayat election to determine the spatial patterns of concentration exhibited by KR contestants as well as KR elected representatives in the study area. Moreover, a non-parametric 'Related-Samples Wilcoxon Signed Rank' Test was conducted on the data of Assembly elections results to infer whether the mean electoral performances of the KR and non-KR groups differ significantly in terms of ranks. Since this data did not fulfil the conditions of normality, a parametric statistical test could not be applied here.

\section{Assessment of the impacts of KR electoral achievements on the movement}

Implications of the electoral achievements of KR candidates upon their movement and vice-versa were primarily assessed from the electoral statistics of Koch Bihar about both Panchayat and Assembly elections. Detailed reviews of relevant literature based on the ISI Web of Knowledge and Google Scholar (scholar.google.co.in) as well as published information from newspapers were also undertaken for this purpose.

Schedule-based surveys through stratified random sampling were conducted among the KR respondents of different C.D. Blocks of Koch Bihar between June 2017 and July 2018 to analyse their perceptions on the impact of their electoral achievements upon the movement. A total of 20 questions comprising both open as well as close-ended ones were asked to at least 10 persons in each C.D. Block to evaluate their perceptions and actions with respect to the movement and the regional electoral politics. The questions were framed to assess if participation in the movement had been influenced by fear of backlash from antagonist political outfits and rival communities. The authors also attempted to ascertain the intensity as well as the type of violence associated with the KR sovereignty movement and identify their spatial patterns all across the study area through these questions. The opinions of the respondents regarding the role of mainstream political parties as well as KR commons in the sovereignty movement were also sought. Among the respondents, opinions of 120 individuals were found to be valid and coherent for further analyses. Moreover, 10 key resource persons were identified within the KR community and were interviewed regarding their involvement in the electoral politics as well as the insurgencies to achieve the same end. They were also asked about the various political alliances made by KR groups during the interview sessions. These resource persons were mostly selected from various parts of the district based on the feedbacks of the locals. The authors' a priori impressions regarding the contention of these resource persons also aided this process.

In this context, it is also necessary to mention that informed consents for inclusion were obtained from all the respondents before they participated in the 
study. Moreover, the study was conducted in accordance with the Declaration of Helsinki, and the protocol was approved by the Doctoral Research Committee of the Faculty of Science in Jadavpur University, West Bengal, India (Index No: 112/16/Geo./24 dated April 28 $8^{\text {th }}$ 2016).

\section{Results}

Results obtained in this study highlighted the persistent struggle of the KR community and consequent upheavals in the regional socio-political setup. Synergic application of qualitative, semi-quantitative and quantitative measures proved to be highly beneficial in this regard.

\section{Status of electoral representation of KR populace}

An exhaustive analysis of the Panchayat election statistics of Koch Bihar (2013) revealed several notable features regarding the political behaviour and electoral success of the KR populace. It was observed that at the lowest GP level, $54.87 \%$ of the total electoral contestants belonged to the KR community. Among them, almost $48.23 \%$ were females. Despite the fact that a high proportion of KR candidates took part in this election, only a meagre $16.45 \%$ of KR males and $12.31 \%$ of KR females were independent candidates. The remaining participants were contesting the elections on behalf of the mainstream political parties having a negligible association with the movement. Notably, KR women were found to be politically lesser active than their male counterparts. Although female participation among the KR contenders was quite high, almost $92.72 \%$ of them were contesting elections from seats reserved particularly for women. Moreover, the proportion of independent KR female candidates was also found to be lower than that of the independent KR males indicating that the KR women were lagging far behind in political emancipation.

At the intermediate PS level of the Panchayat system, most of the candidates again belonged to the KR community (54.47\%). Out of which, $44.68 \%$ were KR females. This difference in gender-participation was noticeably higher at this level than that of the other GP level. However, a trend similar to the previous GP level was observed as far as independent candidature of the KR populace was concerned. Only $19.23 \%$ of the total KR male candidates and a trivial $10.54 \%$ of the total KR female candidates were found to contest the elections as independent ones. The status of KR women remained unimproved at this level since only $6.12 \%$ of the total KR women candidates were contesting the elections from unreserved seats. This was almost akin to the trend at GP level.

Patterns of KR political candidature were not different at the topmost ZP level. Almost $55.73 \%$ of the total contestants were KR candidates containing $45.79 \%$ females. Most of these KR contestants were affiliated to the mainstream parties. Only $36.21 \%$ and $12.24 \%$ of KR males and females respectively were found to contest the elections at the ZP level as independent ones. 


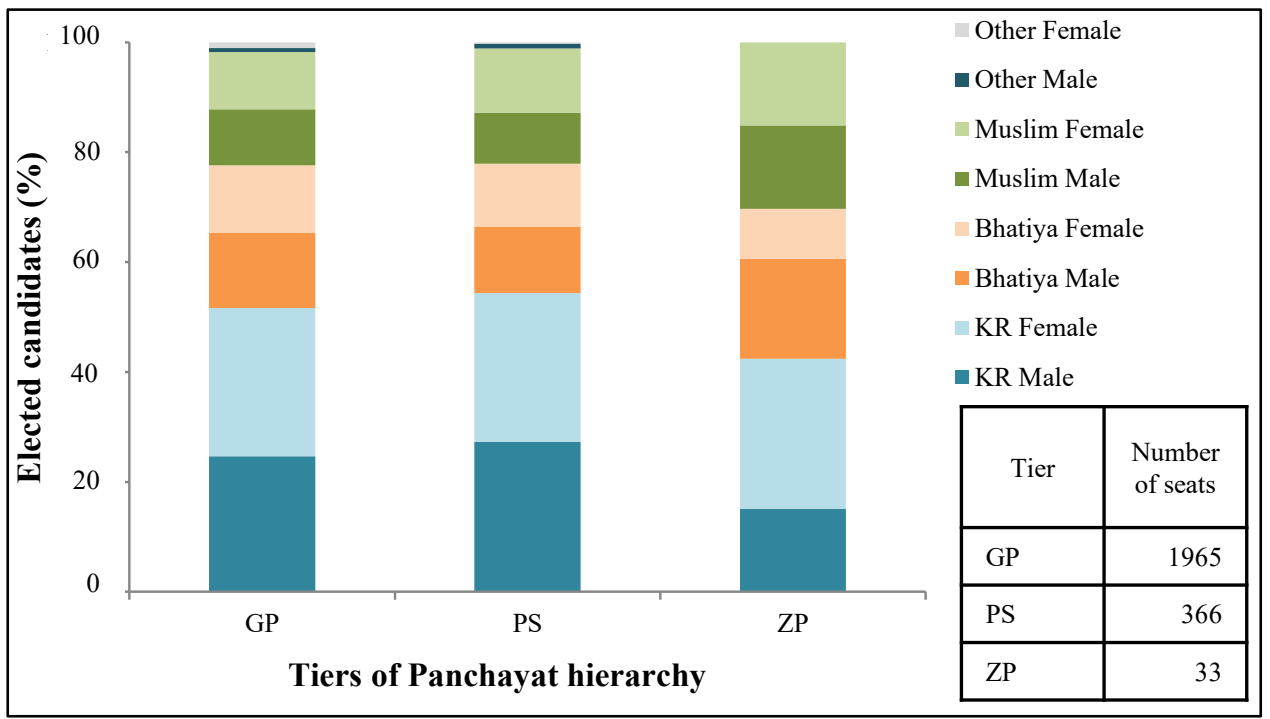

Figure 2. Gender electoral performances of different communities in the Panchayat hierarchy of Koch Bihar

Regarding the results of elections, it was observed that male, as well as female, KR candidates won most seats at the lowest level of GP and the intermediate level of PS in Koch Bihar (Figure 2). In comparison, the performances of Bhatiya candidates were considerably poor at these levels. However, the proportion of winning Bhatiya male candidates was conspicuously higher than that of the KR at the topmost ZP level. Conversely, the number of victorious KR females overshadowed all other communities even at this tier. Other communities consisting primarily of Muslims, indigenous as well as immigrant tribal groups were found to be considerably lagging in electoral representation throughout the Panchayat hierarchy of the district with meagre existence at the topmost tier. Similarly, the proportion of the KR females was marginally higher than that of the KR males at the lowest tier and considerably higher than them at the uppermost tier of the Panchayat hierarchy.

It should be noted that the results at the GP and PS levels were probably influenced by the existence of a sizable proportion (50\%) of total seats explicitly reserved for women. Unfortunately, a similar analysis could not be made for the ZP level due to unavailability of sufficient data. However, reservation did not seem to affect the elected Bhatiya women in a similar manner, as their proportions at all the three levels were lower than that of their KR counterparts. This could be attributed to the facts that a substantial percentage of the total seats reserved for women also belonged to the SC category (40.65\% at GP and $44.89 \%$ at PS levels respectively) and the KR community had the highest population share among all the SCs of Koch Bihar. Location quotients of the Panchayat data of Koch Bihar (2013) indicated that at the GP level, KR participants showed patterns of very high concentrations with respect to the district (ZP) level status only in four GPs of Mekhliganj, five GPs of Mathabhanga-I, one GP of Sitalkuchi, and one GP of Dinhata-II C.D. Blocks (Figure 3a). 


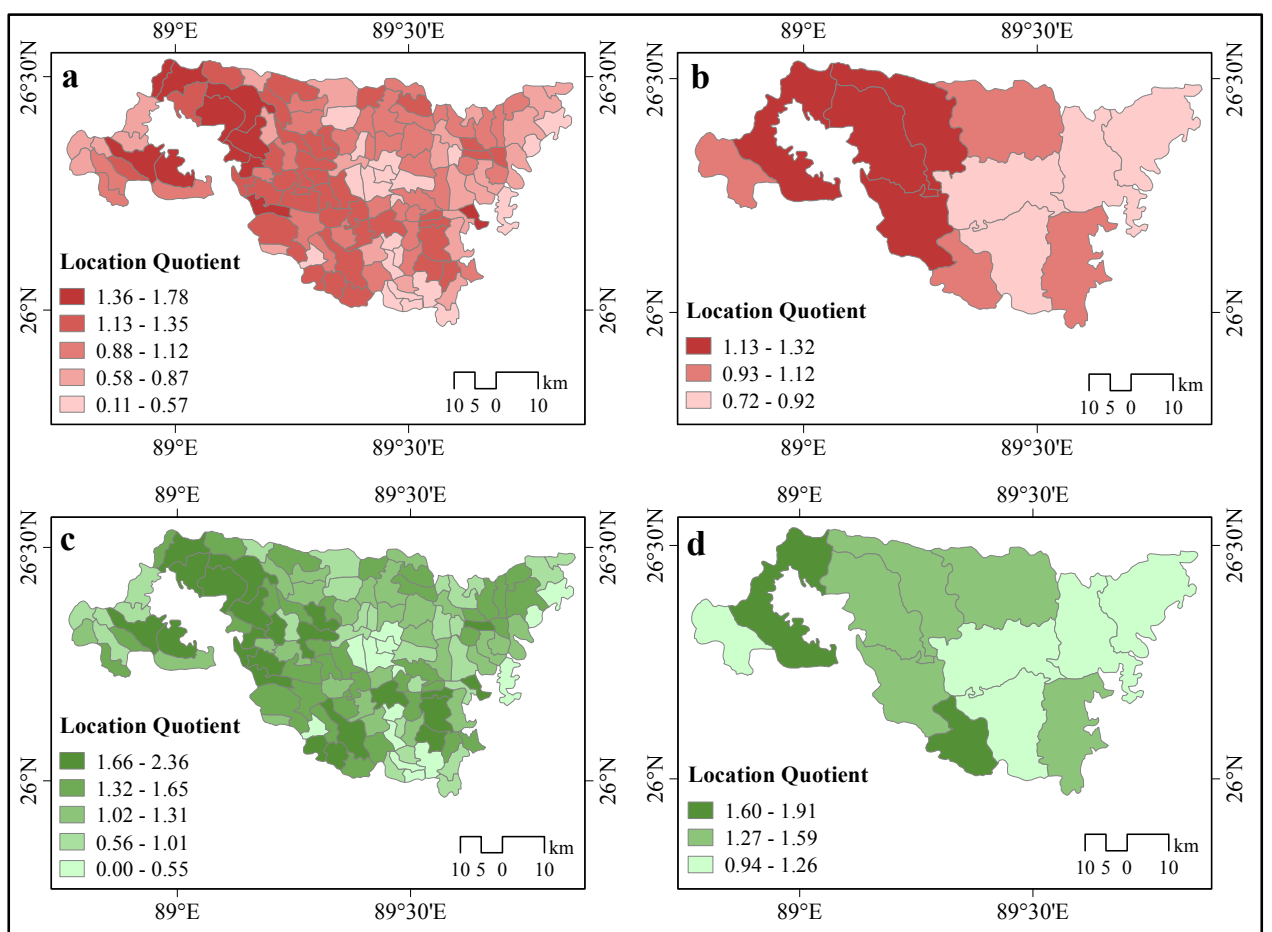

Figure 3. Spatial concentration patterns of KR candidature in Koch Bihar; (a)

Concentrations of KR participants at the GP level; (b) Concentrations of KR participants at the PS level; (c) Concentrations of KR elected representatives at the GP level; (d)

Concentrations of KR elected representatives at the PS level

Most of the GPs of other C.D. Blocks exhibited moderate to high concentrations, whereas few GPs of Dinhata-I, Cooch Behar-I, and Cooch BeharII showed very low concentrations of KR participants. At the PS level, Mekhliganj, Sitalkuchi, Mathabhanga-I, and Mathabhanga-II C.D. Blocks showed high concentrations of KR participants with respect to the ZP level whereas the remaining showed moderate concentrations similar to the scenario at GP level (Figure 3b). Regarding winning candidature, it was found that elected KR representatives at the GP level were concentrated profoundly in most GPs of Mekhliganj, Sitai and Mathabhanga-I as well as in few GPs of Dinhata-I, DinhataII, Mathabhanga-II, Sitalkuchi, and Tufanganj-I C.D. Blocks (Figure 3c). At the PS level, all C.D. Blocks showed moderate to high concentrations of elected KR representatives (Figure $3 \mathrm{~d}$ ). Here, only Mekhliganj and Sitai were found to exhibit very high concentrations of the same. In this context, it should be worthwhile to mention that a major section of the independent candidates of the 2013 Panchayat elections were sympathisers of the KR sovereignty ideologies as revealed through personal interviews of the KR resource persons.

In contrast, the results of the Assembly elections of Koch Bihar from 1962 to 2016 revealed a completely different scenario from that of the Panchayat elections. The temporal data indicated the dominance of the Bhatiya candidates at the Assembly level in comparison to their KR counterparts. The RelatedSamples Wilcoxon Signed Rank Test was conducted in order to determine if there 
was a significant difference between the electoral performances of the KR and non-KR groups in the Assembly elections during the period mentioned above. The Test results showed statistically significant differences between the mean performances of the KR and non-KR groups $(\mathrm{P}<0.05)$. Thus, it could be inferred that although the KR community had performed exceedingly well at the Panchayat elections, they had often been found to lag behind the Bhatiya candidates at the higher and more prestigious Assembly level.

Nevertheless, it must be pointed out that unavailability of consistent data for previous Panchayat elections was a constraint to an efficient comparison of the Panchayat and Assembly elections of Koch Bihar on a temporal scale. Since the Panchayat election results of 2013 were analyzed in detail, comparisons between the Assembly election results of 2011 and 2016 with the former were assumed to be suitable. In 2011 , almost $55.56 \%$ of the total elected candidates at the Assembly level belonged to the Bhatiya community while the remaining $44.44 \%$ were of the KR origin. However, the shares of both groups were found to be equal in 2016 . Even so, this situation was in stark contrast with the Panchayat election results in which the KR candidates dominated at all tiers. In general, the Assembly election results from 1962 to 2016 further consolidated the inference that ethnocracy still prevailed at the topmost political levels of this region.

It also demonstrated that the political party that reigned in the state of West Bengal during a particular timeframe always fared best during the corresponding Assembly elections. Therefore, the KR sovereignty movement was found to be exerting little or no actual impact on these election outcomes. Notably, the proportion of elected Bhatiya candidates was maximum during the 1977-2011 period in which the coalition of leftist parties (Left Front) was in power with an absolute majority (Barman, 2011; Dutt, 2016). The Bhatiya community had garnered maximum socio-economic power in the study area under this regime since many of the intellectual leaders of the Left Front (LF) belonged to this community. Notably, only two female candidates were elected at the Assembly level during the entire period between 1962 and 2016. Incidentally, one belonged to the KR community while the other was a Bhatiya candidate. Moreover, similar to that of Panchayat elections, all wining KR candidates at the Assembly level were found to be partisan to mainstream politics reflecting the relative failure of the sovereignty movement to influence the electoral politics of Koch Bihar (Table 2).

Table 2. Community and gender-wise scenario of electoral successes in the Assemblies of Koch Bihar from 1962 to 2016

\begin{tabular}{ccccccccc}
\hline \multirow{2}{*}{$\begin{array}{c}\text { Political } \\
\text { party }\end{array}$} & \multicolumn{2}{c}{ KR } & \multicolumn{9}{c}{ Number wins from a community } & \multicolumn{2}{c}{ Bhatiya } & \multicolumn{2}{c}{ Muslim } & \multicolumn{2}{c}{ Others } \\
& Male & Female & Male & Female & Male & Female & Male & Female \\
\hline INC $^{1}$ & 12 & - & 13 & - & 4 & - & - & - \\
LF & 25 & 1 & 45 & 3 & 2 & - & - & - \\
AITC & 5 & - & 7 & - & 1 & - & - & - \\
BJP & - & - & - & - & - & - & - & - \\
Independent & - & - & - & - & 1 & - & - & - \\
\hline
\end{tabular}

Source: Elections.in (2018a, 2018b, 2018c, 2018d, 2018e, 2018f, 2018g, 2018h, 2018i, 2018j, 2018k, 2018I, 2018m); Statistics Times (2018); ${ }^{1}$ Indian National Congress 


\section{Roles of associated political groups}

Several political outfits, both moderates as well as extremists, had been concomitant with the KR sovereignty movement during its different phases (Das, 2009). Among these, the Kamatapur People's Party (KPP) and the Greater Cooch Behar People's Association (GCPA) were the notable moderates and the Kamatapur Liberation Organization (KLO) and the All Koch-Rajbanshi Students' Union (AKRSU) were the major extremists working closely with the United Liberation Front of Asom (ULFA). Barring these extremist organizations that could not take part in the democratic electoral process due to their commitment in armed struggles, most of the other KR political groups had made repeated attempts to get involved in electoral politics. They had attempted this either under their banners or in association with mainstream political parties but failed to attain any meaningful positive result until now concerning their political causes (Figure 4).

Among the prominent groups, the GCPA was leading the movement since 2011 although it had never been actively involved in electoral politics. Nevertheless, it had extended holistic support to a right-wing party of mainstream politics, the Bharatiya Janata Party (BJP), during the parliamentary elections in 2014. Subsequently, BJP obtained substantial votes from the KR community. The camaraderie between the GCPA and the BJP stemmed from the fact that the BJP had acknowledged the issue of a separate 'Greater Cooch Behar' state and thereby brightened the possibilities of positive outcomes for the sovereignty movement (Chowdhury and Bhattacharyya, 2016).

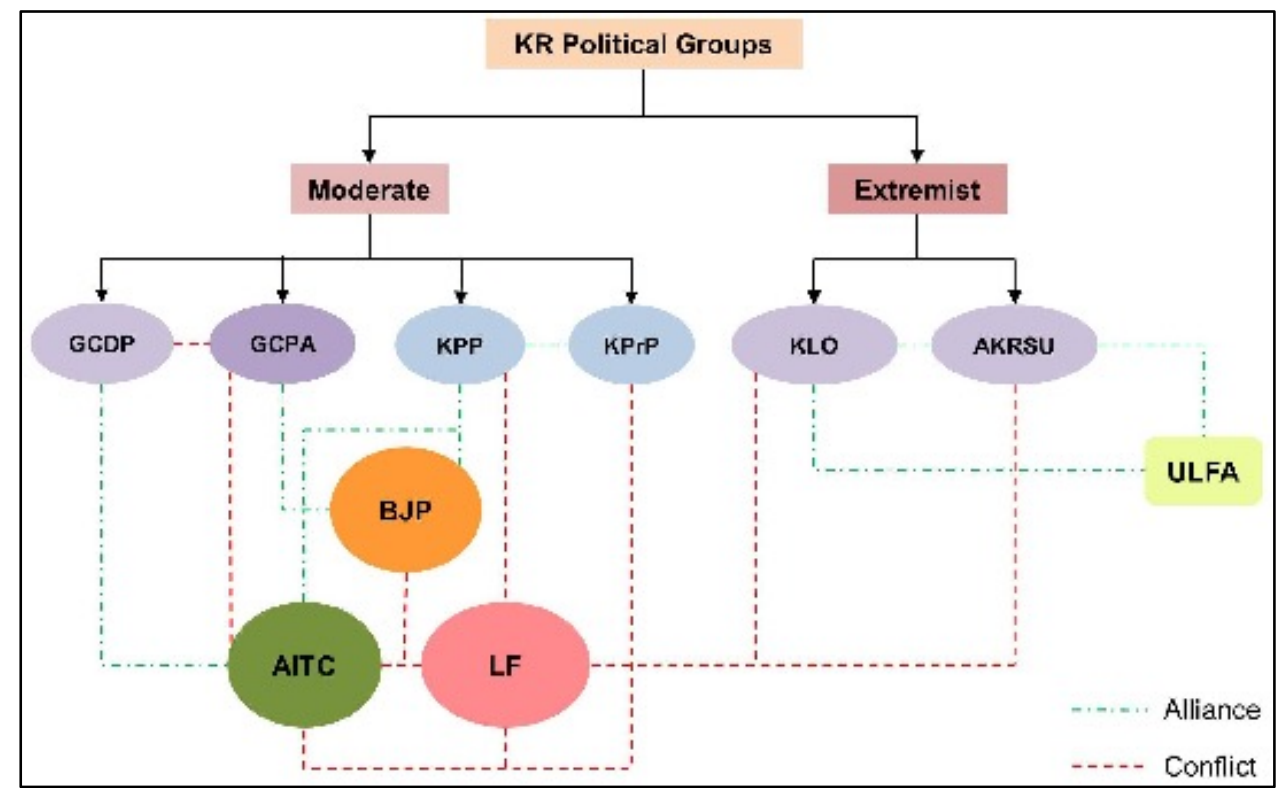

Figure 4. Political alliances and conflicts in the study area 
On the contrary, the Greater Cooch Behar Democratic Party (GCDP), formed by a split faction of the GCPA, had taken an active part in the parliamentary elections of 2009. However, its candidates managed to secure only $3.3 \%$ of the total votes, thereby failing to make any mark in the regional political scenario (Election Commission of India, 2009). In 2016, the GCDP allied with the All India Trinamool Congress (AITC), the present ruling party, since its rival GCPA was supporting the BJP (Datta, 2018).

The political endeavours of the KPP suffered a similar fate like that of GCDP. The KPP put up a united front with the AITC during the Assembly elections of 2001, but the then LF government was able to thwart them with ease (Ray Chaudhuri, 2009). Later, the KPP joined forces with the Jharkhand Mukti Morcha, another separatist political party active in the neighbouring states, in the parliamentary elections of 2004. Once again, the KPP candidate from Koch Bihar suffered a humiliating defeat from the reigning LF. The KPP kept on changing its electoral partners as it supported the BJP in 2014 and teamed with the AITC again in the Panchayat elections of 2018 (Bhattcharya, 2016; Das, 2018). The Kamatapur Progressive Party (KPrP), a new fraction of the KPP, put up its own candidates against the other mainstream parties in 2018. However, the AITC emerged victorious with an overwhelming majority throughout Koch Bihar, thereby highlighting the inability of the KR political groups to achieve electoral success yet again.

\section{Perspectives of the KR commons}

Schedule based perception surveys among the KR respondents revealed that an important section of them (39.17\%) feared conflict with members of the ruling political party if they showed any sympathy towards the sovereignty movement. Another substantial proportion of respondents (25\%) accepted that actual instances of violence between cadres of the ruling party and supporters of the movement had deterred many KR commons from being actively involved in it. However, the occurrence of such blatant violence was denied by $35.83 \%$ of respondents indicating more towards its latent nature (Figure 5). Remarkably, the amount of standard error (SE) was highest for this group of respondents $(0.26)$ among the three options. It actually represented considerable differences of opinions regarding the magnitude of this latent violence even within the group mentioning no conflict.

Focused personal interviews with key KR informants of Koch Bihar further corroborated these findings. A KR member of Panchayat in the Cooch Behar-II C.D. Block stated that he was partially sympathetic towards the issue of sovereignty of his own community. However, he could not show open support towards it being an electoral representative of the ruling party. Instances of violence between the pro and anti-sovereignty parties were reported mostly in Cooch Behar-I, Cooch Behar-II, Mathabhanga-I and Mathabhanga-II C.D. Blocks. Vandalization of houses and other properties, damage and plundering of 
crops, receipt of physical injuries were the major features of this violence from both sides. Notably, even KR individuals affiliated to the ruling party were found to be involved in such acts of violence against their fellow community members. Peaceful protests and demonstrations in favour of the movement had often been disrupted with force thereby inducing anguish among the KR masses. In this context, a noteworthy observation was that of the lack of interest among supporters of the GCPA towards any kind of electoral representation. On the contrary, they were in favour of reinstituting monarchy in the proposed state of 'Greater Cooch Behar'.

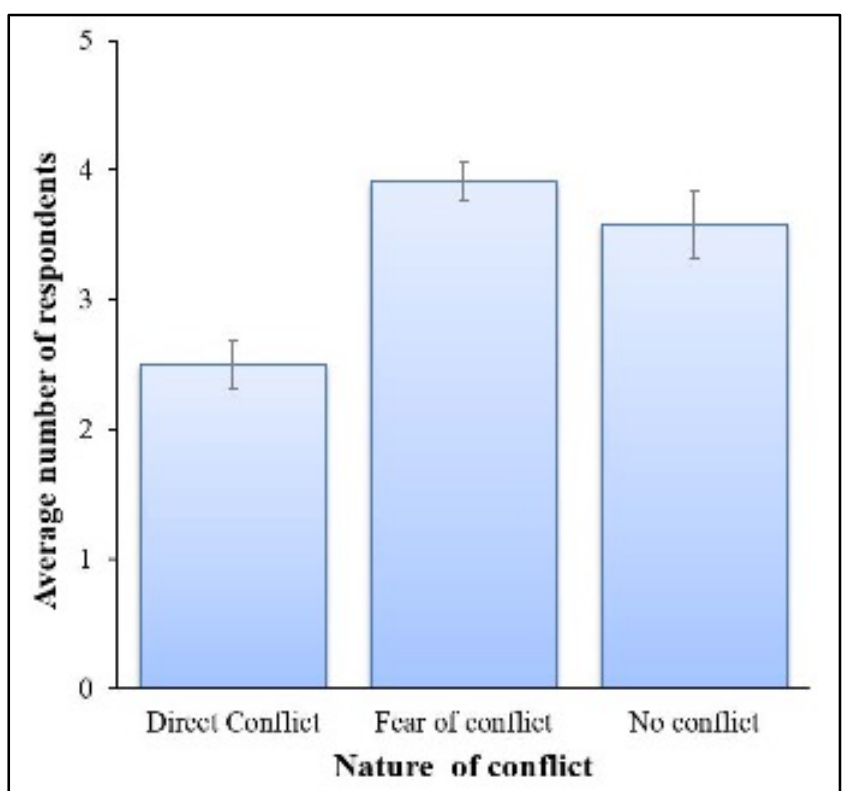

Figure 5. Perception of respondents on the nature of conflicts associated with the sovereignty movement. $\mathrm{N}=120$. Error bars represent $\mathrm{SE}$.

\section{Discussion}

The KR sovereignty movement has spanned over thirty years in north-eastern India with Koch Bihar as its hotbed for last two decades. It was observed in the course of the research that the movement had failed to achieve any substantial success despite its protracted timeframe. The demand for a separate federal unit by the KR community had either been continuously ignored or simply used as a tool to secure a loyal vote bank by all state as well as central governments over the years (Mandal, 2015). Failure of the KR political outfits to achieve electoral success had possibly been the greatest obstacle towards the fulfilment of their demands since the inception of the movement. In most instances of electoral camaraderie, the KR along with the Rabha and Mech communities, served as effective vote banks for the mainstream parties. No concrete effort had ever been made to arrive at an amicable resolution of the sovereignty claims. For instance, the erstwhile LF government of West Bengal was blatantly intolerant towards these separatist 
demands owing to its political ideology that refused to acknowledge the division of societies based on ethnic identities (Guha, 2017). The present state government led by the AITC preferred to follow a policy of appeasement along with disapproval for a separate state chiefly to conserve its larger 'Bengali' vote bank (Ghosal, 2016).

The only positive step taken by the present state government in this regard was to grant official recognition to the language spoken by the KR commons (Datta, 2018). However, members of the ruling party were often found to be engaged in conflicts against active supporters of the movement throughout the study area. Consequently, the fear of backlash was found to have left such severe imprints in peoples' minds that several respondents were not even willing to answer questions relating to their stand on the sovereignty movement. Many of them were unwilling to acknowledge the existence of any connection between them and the KR activists. These findings possibly accounted for the dearth of independent elected KR representatives in the Panchayat elections of Koch Bihar. Among all the mainstream parties, only the BJP led coalition, which has been in power in the central government of India since 2014, was found to be compassionate towards the KR political demands in accordance with its policy of encouraging the formation of smaller states along ethnic lines. However, this sympathy could be viewed chiefly as a larger strategy to strengthen their foothold in Koch Bihar as well as the entire north-eastern India with support of the KR and other tribal communities rather than a sincere endeavour to absorb these offended and deprived indigenous groups into the folds of mainstream society (Bhattacharya, 2016; Das, 2018).

The KR political organisations had met with abysmal failures whenever they tried to contest the elections on their own. Lack of efficient political leadership was found to be the prime cause of such failures. Personal political ambitions of KR leaders coupled with the lack of coordination among different KR political outfits as well as a divided political affinity among the KR commons were the other major factors found to be responsible for their failure (Datta, 2018).

The KR community dominated at all three tiers of the Panchayat hierarchy of Koch Bihar with respect to both participation and victory. However, it did not necessarily mean that these candidates were supporters of the sovereignty movement. For instance, most respondents at Mekhliganj C.D. Block claimed during the personal interactions that they were completely neutral or ignorant about the movement. It was despite the fact that very high concentrations of KR participants, as well as winners, were reported in this particular area with respect to the ZP level. It was observed that these winning individuals were not ready to relinquish their political aspirations for the cause of the movement. It was also noteworthy that the KR candidates could not perform as successfully at the Assembly level as at the Panchayat level since the Bhatiya populace were still dominant at the topmost political echelons.

In general, the dearth of electoral representation for the issue of $\mathrm{KR}$ sovereignty had not only undermined the movement over the years, but it had also been responsible for the continued existence of violence in the study area. 
Being unable to achieve their demands democratically, the KR masses subsequently resorted to fierce agitations, demonstrations, protests as well as brutal acts of violence like kidnapping, extortion, and assassinations. These were more common during the political hegemony of the KLO over the movement until 2003. Since then, the nature of violence had undergone a sea change. It had acquired a somewhat suppressed form and had been generally limited to blockades and protest meetings only. However, even this violence had remained largely unsuccessful in gaining support for sovereignty from the state administration until present (Mehta, 2016).

\section{Conclusions}

In the context of the present research, the paucity of electoral data of Koch Bihar for earlier years was the major obstacle towards more exhaustive analyses. Furthermore, the individual responses of the perception surveys were often influenced by their instinctive lack of trust as well as fear of state-sponsored oppression and thus could not be treated as entirely factual. Notwithstanding these shortcomings, the present paper could safely be recognized as a pioneering endeavour towards unearthing the complexities and ground realities of $\mathrm{KR}$ sovereignty politics in the region.

A comprehensive appraisal of the interrelationships among the issues of KR sovereignty, the practice of violence and the electoral politics of Koch Bihar revealed that achievement of socio-political stability was still a distant dream here. It could not be attained unless the reigning state, as well as central governments and the other mainstream political parties, were genuinely willing to arrive at a peaceful solution instead of fighting for individualistic political gains. Prevalence of acute poverty, deprivation from access to and control of CPRs, and sociocultural marginalisation of the KR, Rabha, and Mech communities were found to be the main impetus to their aspirations of sovereignty. Accordingly, it would be advisable to formulate inclusive economic policies for these indigenous communities in longer terms as well as accommodate them respectably in the mainstream society through social engineering. This would require a multipronged regional planning approach that can include: the augmentation of land reforms and reallocation processes, growth of agro-based industries, scope of micro-finance for small and marginal farmers, realization of regional ecotourism potentials, social cum governmental recognition as well as conservation of ethnic cultural elements (language, religion, customs etc.) and heritages irrespective of the class-caste-gender hierarchies existing in the region. Since the loss of land ownership rights was found to be the root cause behind the economic marginalisation of the KR populace, conferment of the same to them might be recognized as an initiating effort towards achieving socio-economic justice. Provisioning of greater electoral representation of the KR as well as other indigenous communities at the assembly level by mainstream political parties could lead to eventual alleviation of ethnocracy from the regional political 
hierarchy and aid the process of ethnic-social integration. Moreover, awareness should be generated between both the Bhatiya and the native populace to discard their prejudices and accept each other as peaceful cohabitants so that divisive forces could not create social rifts. Conversely, failure to do so would undoubtedly lead to the persistence of violence in the region, thereby, rendering it unsustainable for the commons in the coming years.

\section{Acknowledgements}

The authors express their gratitude towards the inhabitants of Koch Bihar for their assistance during the fieldwork. The financial assistance for carrying out this research was provided by the University Grants Commission, India [UGC-Ref. No.: 3248/(NET-JUNE 2015)].

\section{References}

Barman, A. (2011), "Left rules West Bengal for 34 years and ruins the state", The Economic Times, viewed 27 March 2019, https://urlzs.com/F74CQ.

Barman, J. (2011), "Why Kamtapur State?" in S. Barma (ed.), Socio-Political Movements in North Bengal, Global Vision Publishing House, New Delhi, India, p. 267-295.

Bhadra, M. (2004), "Gender dimensions of tea plantation workers in West Bengal", Indian Anthropologist, vol. 34, no. 2, p. 43-68.

Bhattacharya, P. (2016), "Everyone's wooing Rajbanshis in North Bengal", The Times of India, viewed 22 September 2018, https://urlzs.com/N3XGG.

Brown, D. (1988), "From peripheral communities to ethnic nations: Separatism in Southeast Asia", Pacific Affairs, vol. 61, no. 1, p. 51-77.

Buendia, R.G. (2005), "The state-Moro armed conflict in the Philippines unresolved national question or question of governance?", Asian Journal of Political Science, vol. 13, no. 1, p. 109-138.

Chowdhury, S. and Bhattacharyya, M. (2016), "TMC pries Cooch Behar door with Burman", The Telegraph, viewed 22 September 2018, https://urlzs.com/4AuWw.

Cline, E. (2006), "The insurgency environment in northeast India", Small Wars $\mathcal{E}^{\circ}$ Insurgencies, vol. 17, no. 2, p. 126-147.

Das, A.J. (2009), Kamatapur and the Koch Rajbanshi Imagination, Arunima Deka, Guwahati, India

Das, R. (2018), "Rajbanshi population to support TMC in Panchayat", viewed 23 September 2018, https://urlzs.com/aMtzp.

Datta, R. (2018), "West Bengal: Speaking their language", India Today, viewed 22 September 2018, https://urlzs.com/Ly4c7.

Dunning, T. (2011), "Fighting and voting: Violent conflict and electoral politics", Journal of Conflict Resolution, vol. 55, no. 3, p. 327-339. 
Dutt, I.A. (2016), "West Bengal assembly elections 2016: Here's what worked in Mamata Banerjee's favour", Business Standard, viewed 27 August 2018, https://urlzs.com/uLoQB.

Election Commission of India (2009), General elections, 2009, Election Commission of India, New Delhi, India

Elections.in (2018a), Previous Election Results, viewed 15 January 2018, https://urlzs.com/98n5X.

Elections.in (2018b), Previous Election Results, viewed 15 January 2018, https://urlzs.com/ie3m1.

Elections.in (2018c), Previous Election Results, viewed 15 January 2018, https://urlzs.com/rSc88.

Elections.in (2018d), Previous Election Results, viewed 15 January 2018, https://urlzs.com/jGVUX.

Elections.in (2018e), Previous Election Results, viewed 15 January 2018, https://urlzs.com/Eflto.

Elections.in (2018f), Previous Election Results, viewed 15 January 2018, https://urlzs.com/M1Cmc.

Elections.in (2018g), Previous Election Results, viewed 15 January 2018, https://urlzs.com/HTgE3.

Elections.in (2018h), Previous Election Results, viewed 15 January 2018, https://urlzs.com/nuhya.

Elections.in (2018i), Previous Election Results, viewed 15 January 2018, https://urlzs.com/YDLYT.

Elections.in (2018j), Previous Election Results, viewed 15 January 2018, https://urlzs.com/3RErg.

Elections.in (2018k), Previous Election Results, viewed 15 January 2018, https://urlzs.com/vBV3i.

Elections.in (20181), Previous Election Results, viewed 15 January 2018, https://urlzs.com/6fexz.

Elections.in (2018m), Previous Election Results, viewed 15 January 2018, https://urlzs.com/t1WFF.

Ghosal, A. (2016), "Cooch Behar bypolls: Ananta Rai 'maharaja' demanding separate state may get BJP ticket", viewed 18 September 2018, https://urlzs.com/dAixJ.

GoI (2011), Census of India 2011, Government of India, New Delhi, India.

GoWB (2018), "Institutional development of Panchayat Raj institutions in Cooch Behar", viewed 15 July 2018, https://urlzs.com/bNNCQ.

Guha, A. (2017), "Caste and politics in West Bengal: Traditional limitations and contemporary developments", Contemporary Voice of Dalit, vol. 9, no. 1, p. 27-36.

Mandal, A. (2015), "Little rebellions: Demands, transgressions, and anomalies in the Kamtapur struggle", Sanglap: Journal of Literary and Cultural Inquiry, vol. 1, no. 2, p. 103-126.

Mehta, P. (2016), "Cooch Behar: Collector says protests withdrawn; 15 injured in clashes, death toll reaches 3", viewed 29 February 2016, https://urlzs.com/CeNxm. 
Nandi, R. (2002), Depletion of Natural Forest in a Multi-ethnic Setting: An analysis of Ecology and Social Structure in the Dooars Region of West Bengal, Jawaharlal Nehru University, New Delhi, India.

Ray Chaudhuri, S. (2009), Cooch Behar raises head for separate state, viewed 22 September 2018, https://urlzs.com/D91La.

Sengupta, C. and Datta, D. (2016), "Ethnic conflicts in urban spaces: Contested geographies of Koch-Rajbanshi identity politics in West Bengal and Assam" in M. Bardhan (ed), Changing Urban Scenario and Emerging Conflicts in Post Globalisation India, Pakhir Akash Prokashani, Kolkata, India, p. 15-26.

South Asia Terrorism Portal (2018), Kamtapur Liberation Organisation (KLO), Institute for Conflict Management, viewed 14 January 2018, https://urlzs.com/XTLYb.

South, A. (2008), Ethnic Politics in Burma: States of Conflict, Routledge, London, United Kingdom

Statistics Time (2018), West Bengal Assembly Election Results, viewed 15 January 2018, https://urlzs.com/lgjP2.

Tan-Mullins, M. (2006), "Voices from Pattani: Fears, suspicion, and confusion", Critical Asian Studies, vol. 38, no. 1, p. 145-150.

West Bengal State Election Commission (2017), West Bengal Panchayat election results-2013, viewed 10 January 2017, https://urlzs.com/AEH89. 